\title{
THEORETICAL AND EXPERIMENTAL ANALYSIS OF MINE ELEVATOR DYNAMIC CHARACTERISTICS
}

\author{
Jovan Vladić, Miomir Jovanović, Radomir Đokić, Milan Kljajin, Mirko Karakašić
}

Original scientific paper

The paper presents the issues with the dynamic analysis of mine elevators used with underground exploitation of raw materials. Dynamic occurrences are particularly emphasized with those elevators due to the fact that they are facilities with extreme heights (up to $2000 \mathrm{~m}$ ) and lifting speeds (up to $20 \mathrm{~m} / \mathrm{s}$ ) using the steel ropes. It shows the forming path of a competent dynamic model for the analysis of such elevators. Basic parameters (stiffness and damping) are of variable magnitude during the lifting, so their values are defined through a combination of theoretical analysis and performed experiments at RTB mine elevators at the town of Bor (Serbia).

Keywords: damping; dynamic model; experimental analysis; mine elevators; stiffness

\section{Teorijsko-eksperimentalna analiza dinamičkih karakteristika rudničkih liftova}

Izvorni znanstveni članak

U radu je prezentirana problematika dinamičke analize rudničkih liftova koji se koriste pri podzemnoj eksploataciji sirovina. Kod ovih postrojenja posebno su izražene dinamičke pojave, jer se radi o postrojenjima s ekstremnim visinama (do $2000 \mathrm{~m}$ ) i brzinama dizanja (do $20 \mathrm{~m} / \mathrm{s}$ ) pomoću čeličnih užadi. Prikazan je postupak formiranja mjerodavnog dinamičkog modela za analizu ovakvih postrojenja. Osnovni parametri (krutost i prigušenje) su, u toku dizanja, promjenjive veličine i njihove vrijednosti su određene kombiniranjem teorijske analize i realiziranih eksperimenata na rudničkom liftu u RTB u Boru (Srbija)

Ključne riječi: dinamički model; eksperimentalna analiza; krutost; prigušenje; rudnički liftovi

\section{Introduction}

Advancements of the science and technological development, as well as the demands concerning capacity increase, have consequently developed a need for elevators and mine elevators with the velocities up to 20 $\mathrm{m} / \mathrm{s}$ and with pronounced dynamic loads, what causes a problem of the right choice and definition of basic parameters of the facilities, especially regarding their reliability, i.e. operating safety.

The mine elevators are used to interconnect different mine horizons by using a mine cage (which is moved between at least two firmly set guide rails), whose dimensions and construction enable ore loading and are approachable to people.

The mines use two systems, one with a drum and the other with a driving pulley (Koepe system). Figs. 1 and 2 provide a scheme of the most applied lifting systems in mine facilities with a driving drum and a friction mechanism (Koepe system).

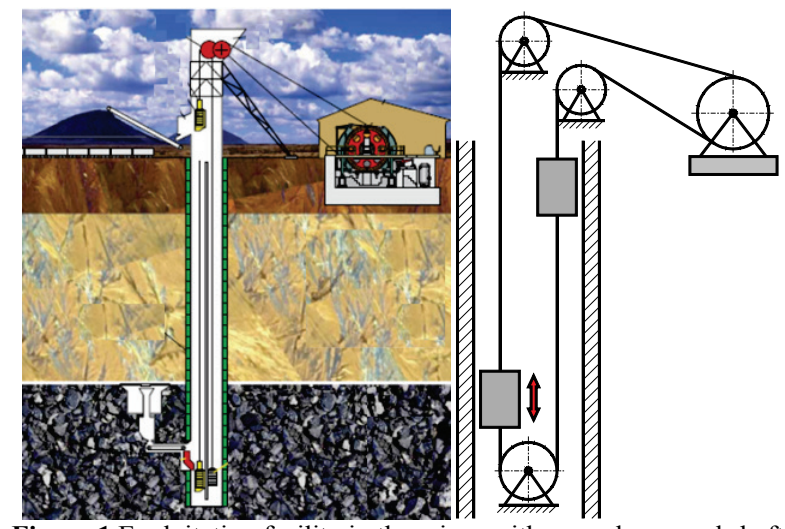

Figure 1 Exploitation facility in the mines with an underground shaf

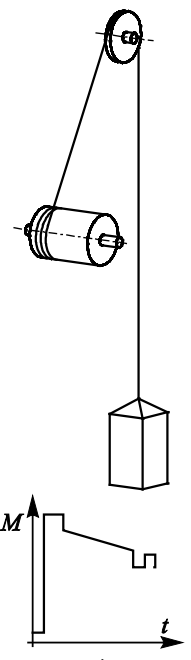

a)
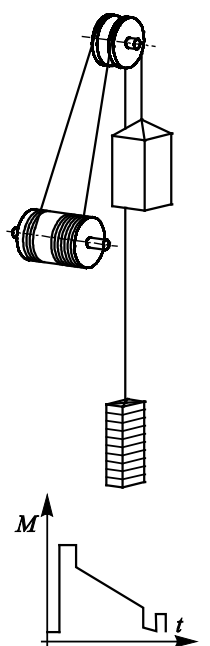

b)

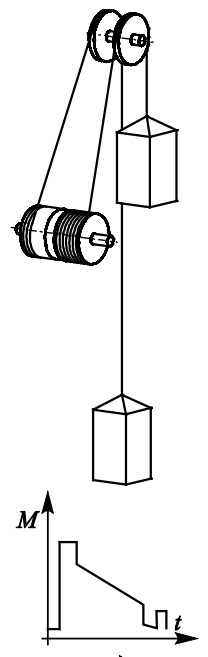

c)

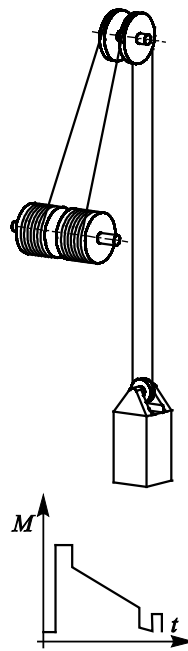

d)
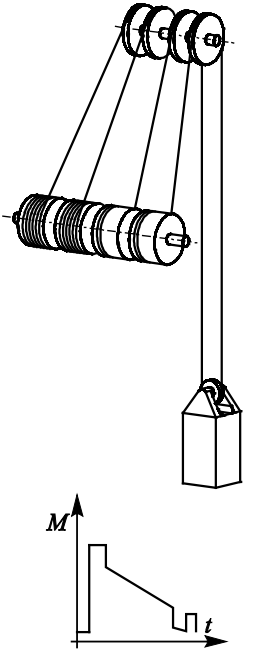

e)
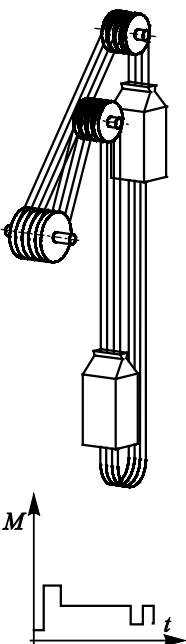

f)

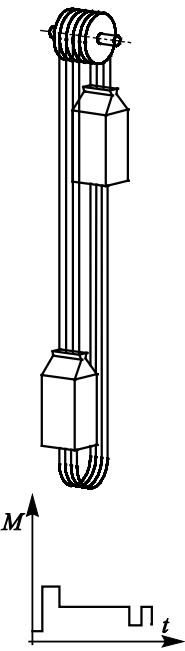

g)

Figure 2 Lifting systems with a drum and Koepe system 
In the systems with a lifting drum, the carrying ropes are wound and stored on a drum. The lifting system with one drum (Figs. 2a and 2b), due to the heavy load and a necessary big length of the drum, is less applicable. However, the system with two drums (Fig. 2c) allows lifting of two separate "loads" in the same shaft (e.g. one "load" can be a cabin, and the other counterweight, which is the case with standard elevators, or there are many instances in the mines when both of the "loads" can be "useful" - one cabin is being lifted while the other is being lowered). The drums are located in the machine room which is usually sideways of the mine shaft, and the ropes go down from it over the deflector pulleys into the shaft next to the cabin. The multiropes lifting system (Fig. $2 \mathrm{~d}, 2 \mathrm{e})$ with the mine elevators is actually a variation of the lifting system with two drums. They are used for bigger loads and in relatively deep pits.

Friction lifting systems (Koepe) are mostly used in European mines. The drive is set above (Fig. 2g) or sideways to the mineshaft. In the case when it is located sideways (Fig. 2f) deflector pulleys are used and they are set above the mine cage (cabin) and the counterweight. The main advantages of the system are decreasing of a driving motor, i.e. necessary torque, a simpler usage of a higher number of steel ropes and the possibility of setting the driving pulley directly above the mine shaft. However, due to the limitations in contact pressure $(1,75 \mathrm{MPa})$ and the limits of slipping $\left(S_{1} / S_{2} \leq 1,4\right)$ between the ropes and the pulley, the advantages are lost, so in practice both systems are applied almost equally.

\section{Forming a suitable model for the dynamic analysis of mine elevators}

As it was mentioned before, the characteristic features of mine elevators are reflected in high lifting heights up to $2000 \mathrm{~m}$ and the velocity up to $20 \mathrm{~m} / \mathrm{s}$ (max $19,2 \mathrm{~m} / \mathrm{s}$ [5]. This paper deals with Koepe system because the experiments were performed on a mine elevator in RTB Bor mine (Serbia). The basic dynamic model for this system is shown in Fig. 3a. Nevertheless, if one looks at the regular operation of the facility, without the slipping of the steel rope in a driving pulley, and if as the driving characteristic is accepted rope velocity at the moment of rope upcoming the pulley (measuring the velocity of the pulley), the model of the mine elevator can be represented in the form shown in Fig. $3 b$.

This model shows a system with longitudinal oscillations of a "heavy" steel rope with an infinite number of degrees of freedom (DOF), which is at one end wound onto a pulley at a velocity $v(t)$, while it is loaded with a concentrated mass on the other end. Forming a representative model for the analysis of dynamic behaviour implies simplification of the model so as to exclude the small influences of the "higher" order and to keep only the most influential (representative) parameters [9]. Apart from that, the analysis considers the particularities of basic mechanical characteristics of a steel rope (stiffness and damping) as dominant elements in the dynamic model. In addition, it discusses the driving features of the pulley. The analysis is based on establishing the parameters for a specific example of a mine elevator in RTB Bor mine. More details on the facility are given in Chapter 3 .

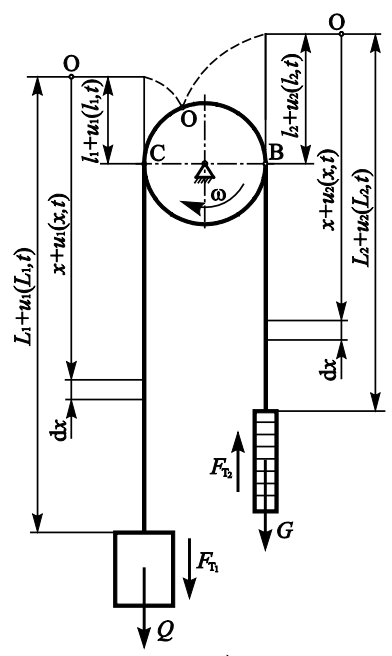

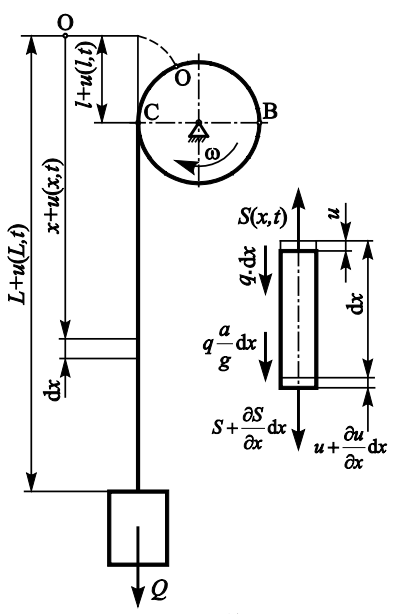

b)
Figure 3 Oscillation of the constant length rope, basic model (a), reduced model (b)

\subsection{Reduction of the number of degrees of freedom}

Deformation of the arbitrary cross section is represented as a function of position $x$ and time $t$, i.e.:

$u=f(x, t)$.

By observing the balance of the elementary part $(\mathrm{d} x)$ it can be noted that:

$$
\frac{q \cdot \mathrm{d} x}{g} \cdot \frac{\partial^{2} u(x, t)}{\partial t^{2}}=-S+S+\frac{\partial S}{\partial x} \mathrm{~d} x+q \cdot \mathrm{d} x \pm \frac{q \cdot \mathrm{d} x}{g} \cdot a .
$$

If the axial force $S$ is described as a relative deformation function $\varepsilon=\partial u / \partial x$, for the case of damping oscillations:

$S=E \cdot A \cdot \frac{\partial}{\partial x} \cdot\left[1+b \cdot \frac{\partial}{\partial t}\right] \cdot \varepsilon$

and if the Eq. (2) is divided by $\frac{q \cdot \mathrm{d} x}{g}$, we get:

$\frac{\partial^{2} u(x, t)}{\partial t^{2}}=\frac{g \cdot E \cdot A}{q} \cdot \frac{\partial^{2}}{\partial x^{2}}\left(u(x, t)+b \cdot \frac{\partial u(x, t)}{\partial t}\right)+g-a$

where: $E$ - elasticity modulus, $\mathrm{MPa} ; A$ - rope crosssection, $\mathrm{mm}^{2} ; u$ - rope elastic deformations, $\mathrm{mm} ; b-$ damping parameter, $\mathrm{N} \cdot \mathrm{s} / \mathrm{m} ; q$-rope weight pro meter, $\mathrm{N} / \mathrm{m} ; a-$ driving mechanism acceleration (at the point where the rope meets the driving pulley), $\mathrm{m} / \mathrm{s}^{2}$.

In order to define the oscillation forms we shall observe the simplified Eq. (4) without two last parts on the right side, which corresponds to the rope oscillation after stopping the pulley. In that case the solution to the equation can be seen as a multiplication of the two 
functions, where one is a position function and the other is a time function [6], in the following form:

$u(x, t)=X(x) \cdot T(t)$

If we take $\frac{g \cdot E \cdot A}{q}=c^{2}$, where $c$ is the propagation velocity of the elastic wave throughout the rope, the Eq. (5) is differentiated in time and place, and it is inserted in the simplified Eq. (4), so we perform the separation of the variables, and we get that:

$\frac{\ddot{T}}{c^{2}(T+b \cdot \dot{T})}=\frac{X^{\prime \prime}}{X}=-k^{2}$,

where $k$ is the constant which is independent of time and position. That evolves into two common differential equations:

$$
\begin{aligned}
& \ddot{T}+b \cdot k^{2} \cdot c^{2} \cdot \dot{T}+k^{2} \cdot c^{2} \cdot T=0 \\
& X^{\prime \prime}+k^{2} \cdot X=0
\end{aligned}
$$

A more detailed solving procedure of differential equations with boundary conditions is provided in $[5,11]$. The solution to the other equation defining the basic oscillation forms of specific harmonics is as follows:

$$
X(x)=A_{i} \cdot \sin \beta_{i} \cdot \frac{x-l}{L-l}
$$

where we get a frequency equation in the form of:

$$
\beta_{i} \cdot \tan \left(\beta_{i}\right)=\alpha
$$

with

$\beta_{i}=k \cdot(L-l)$

$\alpha=\frac{q \cdot(L-l)}{Q}-$ represents the weight ratio between the rope's free length and the car.

For different ratios of the rope weight and the load it is possible to find the solutions for the transcendental Eq. (9) by using the calculation methods or graphically. It has an infinite number of roots, therefore the number of its own circular frequencies is indefinitely large.

The limiting values for $\alpha$ (in the specific mine elevator in RTB Bor mine) are given in Tab. 1. A small weight of the rope's free length in comparison to the concentrated mass greatly simplifies the analysis of the dynamic behaviour of mine elevators.

Table1 Boundary values for $\alpha$

\begin{tabular}{|c|c|c|c|}
\hline \multirow{2}{*}{$\alpha$} & \multicolumn{2}{c|}{ Cage position } \\
\cline { 3 - 4 } & & up & down \\
\hline \multirow{2}{*}{ Cage state } & empty & 0,0064 & 0,32 \\
\cline { 2 - 4 } & loaded & 0,0036 & 0,18 \\
\hline
\end{tabular}

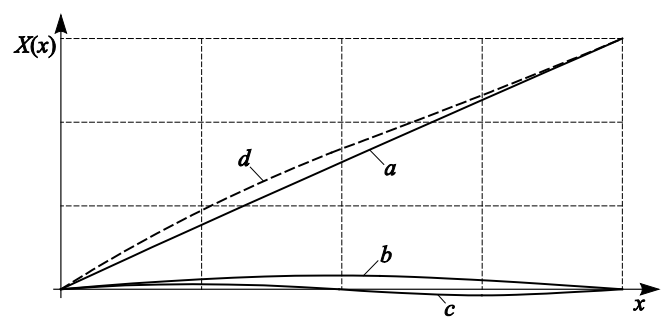

Figure 4 The oscillations forms of the first three harmonics (a,b, and c) and the collective oscillation form for $\alpha=0,1$

Due to the fact that oscillation amplitudes of higher harmonics are rather small, their influence can be neglected, so the whole oscillation process, represented in Eq. (4) with an infinite number of DOF, whose collective oscillation form is shown in Fig. 4 as a broken line $d$, can be satisfactorily accurate if replaced with a straight line $a$, i.e. a system with one DOF with a constant dilatation $\varepsilon$ down the free end of the rope.

\subsection{Mechanical characteristics of the wire rope}

Modelling of the wire rope is most commonly executed through a so-called Kelvin's model which represents a parallel arrangement of an ideally elastic body and an ideally viscous body. Stiffness $c$ and damping $b$, as parameters of the model, are usually defined through an elasticity modulus and a damping coefficient for homogenous bodies (steel, aluminium...). Due to the specific construction of the steel rope, the definition process of these parameters is very complicated. Consequently, we use in practice the approximate data which is gained on the basis of "extrapolation" of experimental results obtained in certain conditions (mostly static) which could lead to significant inaccuracies in the dynamic analysis of hoisting machines in mines [8].

\subsubsection{Stiffness and rope elasticity modulus}

Stiffness is the basic parameter of oscillatory processes and it represents a feature of a material that defines the ratio between load and deformation. It is viewed as a constant matter in most oscillatory processes with small amplitudes and elements made of steel and similar materials. On the other hand, it is a case with some materials also used in mechanical engineering that the feature is not linear, which brings to the occurrence of the so-called non-linear oscillations whose analysis is more complex on numerous levels. A specific case of non-linearity happens at the lifting machines with steel ropes and it refers to the fact that the stiffness changes together with the change in the ropes' free lengths in the following relation:

$c(t)=\frac{E \cdot A}{l(t)}$,

where: $E$ - elasticity modulus, $\mathrm{MPa} ; A$ - rope crosssection area, $\mathrm{mm}^{2} ; l(t)=L-\int v(t) \mathrm{d} t-$ free rope length, $\mathrm{m}$; $v(t)$ - circumferential velocity on the pulley, $\mathrm{m} / \mathrm{s}$. 
Apart from the variable stiffness, attention should be paid to the elasticity modulus $\boldsymbol{E}$, which is much more difficult to define in comparison with the homogenous bodies since the steel rope is a complex structure, consisting of a large number of wires layered into strands, while the strands are stranded into a rope with the core made of steel or fibre.

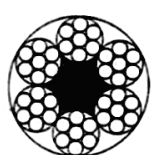

$6 \times 7$

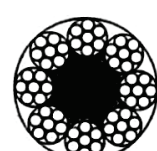

$8 \times 7$

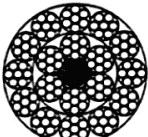

$18 \times 7$

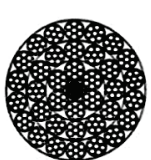

$36 \times 7$
Figure 5 Different construc

There are different expressions mentioned in the literature $[2,4]$ for its calculation depending on the wire elasticity modulus and the angles at which the wires lay into a strand, and strands into a rope. These expressions only give approximate data because the real magnitudes of the elasticity modulus, apart from the above mentioned parameters, depend on the stress magnitude, core material, time spent in service (the number of load cycles), types of wire connections etc. Fig. 6 shows the experimental results [2] which show a noticeable difference in the results between the first loading of the rope (new rope), and after 10 loadings (Fig. 6a), and also the effect of the stress level with the loading and unloading in Fig. $6 \mathrm{~b}$.

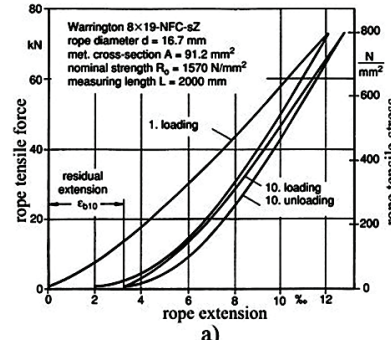

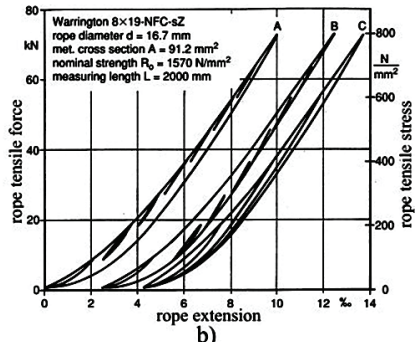

b)
Figure 6 Experimentally determined elasticity modulus [2]

Nevertheless, the application of the results generated in this way is disputable when it comes to dynamic processes. Adequate elasticity modulus values for the ropes in exploitation can be gained through direct measuring in the real working conditions of the elevator facilities. By using the functional dependence between the stiffness $c$, circular frequency $\omega$, and elasticity modulus $E$, for the case of free oscillations with damping, there can be determined an elasticity modulus value by putting oscillations period $T$, i.e. frequency $f$, from the diagrams which were experimentally obtained (Fig.7), in the equation:

$E=\frac{l \cdot \omega^{2} \cdot M_{\mathrm{e}}}{A}=\frac{4 \cdot \pi^{2} \cdot l \cdot M_{e}}{A \cdot T^{2}}$

where: $\omega=2 \pi f=\frac{2 \pi}{T}$ - circular frequency, $\mathrm{rad} / \mathrm{s} ; T$ oscillation period (measured value), Fig. 7, s; $M_{\mathrm{e}}=M+q \cdot \frac{L-2 \cdot l}{3}$-reduced oscillatory mass, $\mathrm{kg} ; A$ rope cross-section area, $\mathrm{mm}^{2}$.

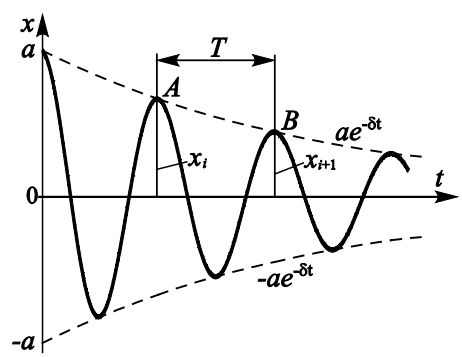

Figure 7 Amplitudes and the period of damped oscillations

\subsubsection{Damping with the wire rope}

There are three damping forms within the oscillations of the mechanical systems [3]:

- inner damping in the material,

- Coulomb (dry) friction and

- environment resistance (fluid damping).

The inner damping comes in two forms: as a pure viscous damping, and as a consequence of the internal friction in the material, a.k.a. hysteretic [3].

Viscous damping, where the damping force is proportional to the velocity, is the most common way to define the influence of inner damping:

$$
\begin{gathered}
F_{\mathrm{v}}=b \cdot \dot{x} \\
m \ddot{x}+b \dot{x}+c x=0
\end{gathered}
$$

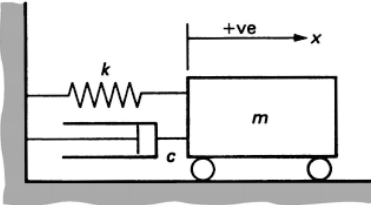

Figure 8 Oscillatory system with viscous damping [1]

Hysteretic damping is a damping which happens because of the internal friction within the material structure (hysteretic), Fig. 9. In contrast to the viscous damping, the damping force in this case does not depend on the frequency. It depends on the surface of hysteretic, i.e. the loss of energy in periodic loading.
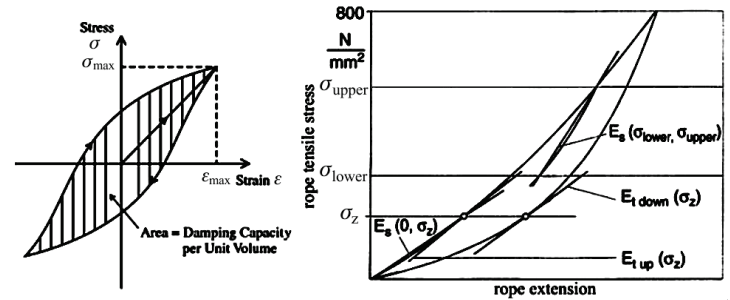

Figure 9 Hysteretic surfaces in homogenous materials and wire ropes [2]

$$
m \ddot{x}+\left(\frac{b_{\mathrm{h}}}{\omega}\right) \dot{x}+c x=0
$$

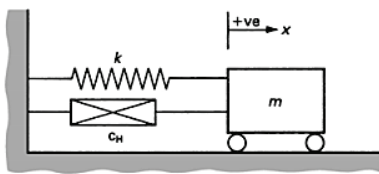

Figure 10 System with a hysteretic damping [1]

It should be expected that hysteretic damping is more common with steel ropes (just like with the homogenous materials - metals). Attention should be paid that the damping magnitude does not depend on the hysteretic form, but its surface. However, due to the complex construction, especially in the ropes with the fibre core, a viscous damping can play a role, too. For now, there are no significant results, so it would be a good idea to do experimental research of this parameter in wire ropes. 
Coulomb damping in the mine elevators occurs in the guide rails of cage and counterweight, Fig. 11. The friction force can be used as a constant value which depends on the friction coefficient and the normal force with the direction opposite of the movement. With the centrical hanging of the cage, the value of normal force depends on the value of springs preload of the wheels. With eccentrical hanging (e.g. rucksack system) and eccentrical position of the load in the car, the normal force depends on the structural parameters of the car and it can be large.

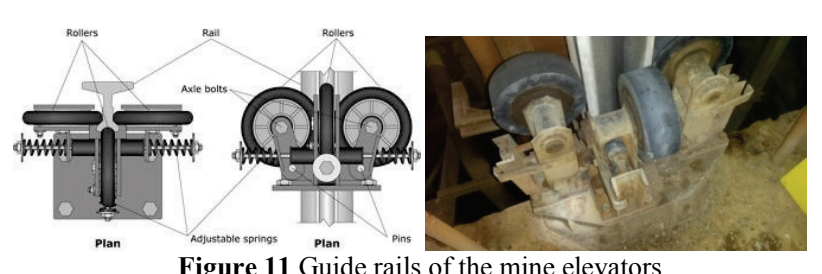

Figure 11 Guide rails of the mine elevators

$$
m \ddot{x}+c x=\mu F_{\mathrm{N}}(\operatorname{sign} \dot{x})
$$

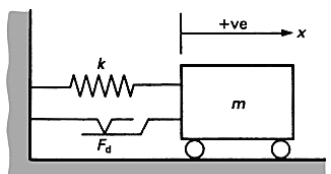

Figure 12 System with Coulomb damping [1]

It can be said that in the case of the observed mine machine in the experiment the mine cage loading was centrical, so the overall force of Coulomb friction on the guide rails is:

$$
F_{\mathrm{T}}=n_{\mathrm{v}} \cdot n_{\mathrm{t}} \cdot \mu \cdot F_{\mathrm{N}}
$$

where: $n_{\mathrm{v}}$ - number of the group of wheels for guidance (two guide rails); $n_{\mathrm{t}}=3-$ the number of wheels in the group for guidance; $\mu$ - resistance of the rolling of the wheel on the guide rail; $F_{\mathrm{N}}$ - pressure force on the guide rail for centrical loading, depending on the preload of springs during assembly, $\mathrm{N}$.

When it comes to smaller accelerations and bigger load of the railing wheels, or the eccentrical loading of the car, the damping cannot be ignored. Fig. 13 shows an illustration which is an example of how the friction in the rails can affect the oscillations of the cage in mine elevators when: $a=0,5 \mathrm{~m} / \mathrm{s}^{2}$ and $F_{\mathrm{N}}=500 \mathrm{~N}$.

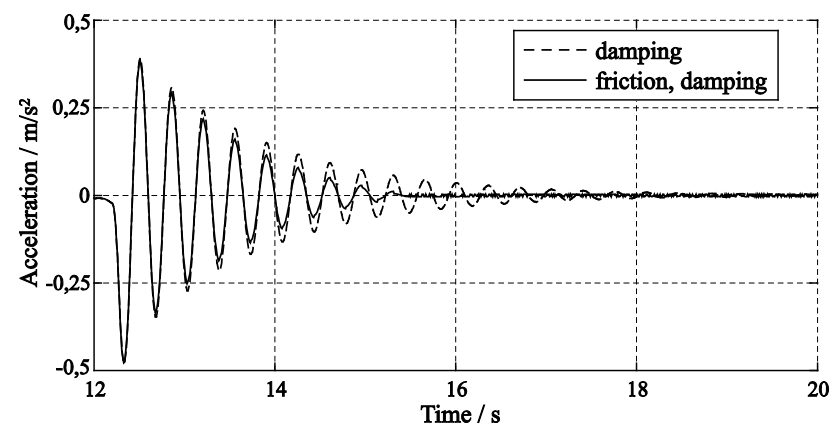

Figure 13 Diagram of the influence of Coulomb friction on the overall damping

Fluid damping occurs with mine elevators because air fluctuates when the cage oscillates in the shaft. The air resistance force is:
$F_{\mathrm{v}}=c \cdot A \cdot q$

where: $c=1,4$ - obstruction coefficient; $A=16 \mathrm{~m}^{2}$ - mine cage cross-section area; $q=\frac{\dot{x}^{2}}{1,6} \mathrm{~Pa}$ - air pressure during an oscillation; $\dot{x}$ - mine cage oscillation velocity, $\mathrm{m} / \mathrm{s}$.

Since the force of the viscous friction is $F_{\mathrm{v}}=b \cdot \dot{x}$, the influence of air damping while the cage is in oscillation can be estimated from:

$\frac{F_{\mathrm{F}}}{F_{\mathrm{v}}}=\frac{c \cdot A \cdot \dot{x}}{1,6 \cdot b}=2,6 \cdot 10^{-3}$

For the discussed machinery, the biggest influence of fluid damping happens when the inner damping is minimal and the oscillation velocity is at its maximum. Since the oscillation speed for a mine elevator in recommended stopping conditions does not go over $1 \mathrm{~m} / \mathrm{s}$, it can be concluded that the influence is less than $1 \%$ and it can be ignored.

In addition to that, it can be concluded that in the analysis of dynamic behaviour of the mine elevators the damping can be modelled as damping consisting of an inner damping of the hysteretic type and Coulomb damping occurring in the guide rails of the cage.

Similar to the elasticity modulus, the overall damping coefficient can be defined by measuring the oscillations of the mine elevators cage. Based on the theory of free harmonic oscillations with the damping, measuring oscillation amplitude, Fig. 7, a logarithm decrement can be defined, and from there on damping coefficients using the:

$$
\begin{aligned}
& D=\ln \frac{x_{i}}{x_{i+1}}=\frac{1}{n} \ln \frac{x_{i}}{x_{i+n}}=\delta \cdot T \\
& \delta=\frac{D}{T}
\end{aligned}
$$

so the damping parameter is:

$b=2 \cdot \delta \cdot M_{\mathrm{e}}$

where: $x_{i}, x_{i+1}$ and $x_{i+n}-$ measured amplitudes, $\mathrm{m} / \mathrm{s}^{2} ; T-$ measured oscillation period, $\mathrm{s} ; M_{\mathrm{e}}$ - reduced oscillatory mass (mass of the cage, load and section of the ropes), $\mathrm{kg}$.

\subsection{Driving characteristics}

Drive, or the necessary movement of the mine elevator, can be modelled through a driving torque, Fig. 14a or through a so-called kinematic condition on the driving pulley, Fig. 14b.

Because of the significant difference in stiffness of the ropes and elements of the driving mechanism, they can be observed as being absolutely stiff with the reduction of the mass and moments of inertia on the shaft of the pulley. If all the characteristics of the driving mechanism are known, it is possible to perform a dynamic analysis by setting the moments and inertia characteristics on the shaft of the pulley [7]. 


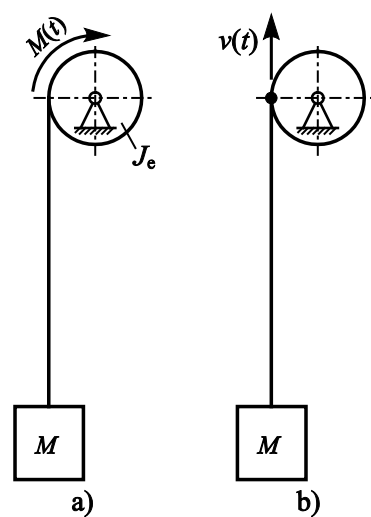

dels of the drive, a) with a driving torque and b) with a lifting velocity

Boundary values of certain kinematic parameters are consequence of boundaries, which are characteristic for some machine types. The recommended maximum velocities with mine elevators are $18 \mathrm{~m} / \mathrm{s}$, even though there were some elevator facilities with $19,2 \mathrm{~m} / \mathrm{s}[5,7]$. The acceleration in cases when the elevators are used for people transport should not exceed $1 \mathrm{~m} / \mathrm{s}^{2}$, although, for example with slow elevators and when using asynchronous motors (with direct start), the maximum accelerations exceed the value of $1,4 \mathrm{~m} / \mathrm{s}^{2}$, and they can even go up to $2,5 \mathrm{~m} / \mathrm{s}^{2}$ [5]. With those elevators that have high velocities, special attention is paid to the "comfort of driving", so, in addition to the boundaries in velocity and acceleration, the value of the acceleration change overtime, the so-called jerk, is limited as well. Fig. 15 shows the common diagrams of velocity, acceleration and jerk.

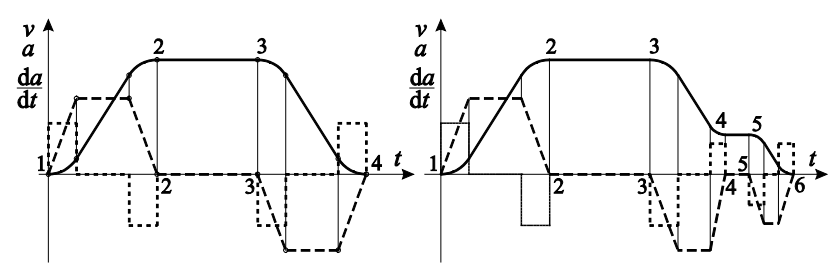

Figure 15 Examples of the diagram of movement for one (a) and two (b) velocities of motor

Modelling in kinematic conditions implies understanding the lifting velocity which in this paper is guaranteed by measuring the circumferential velocity of the pulley, at the point where the rope is meeting the driving pulley (calculated velocity, based on the measured value on the brake disc circumference).

\subsection{Suitable dynamic model for mine elevators}

Based on the previous analysis, in the case of Koepe type mine elevators, with a driving pulley above the shaft, a suitable model for the dynamic analysis can be defined in the form given in Fig. 16.

A suitable model represents an oscillatory system with one DOF, with the ropes that are described with an equivalent Kelvin's model where the stiffness during lifting is changed in accordance with the rope's free length while, at the same time, damping is of the hysteretic type with the friction of the guide rails included in it [13]. The mass is taken as a constant for a specific oscillatory process, but different options are considered (an empty car, full car and the reduced rope weight). Defining the parameters for the model was performed by combining the well-known theoretical relations for free oscillations with damping together with the measuring results of the mine elevator in RTB Bor, which is described in the following chapter.

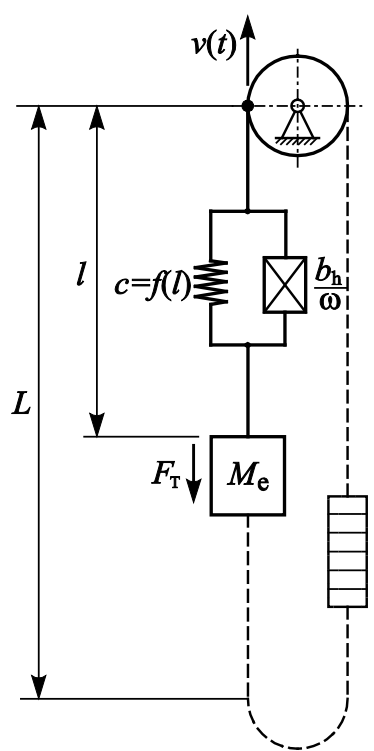

Figure 16 Suitable dynamic model for the analysis of the elevator facilitiy in RTB Bor mine

\section{Experimental research on the mine elevator}

The experiments were performed on the mine exploitation machine with the lifting capacity of $22 \mathrm{t}$ (shown in Fig. 17). Its features are: mass of the empty cage $-13 \mathrm{t}$, mass of the counterweight (adjustable) $18 \div$ $23 \mathrm{t}, 6$ ropes $(27 \mathrm{~mm}$ diameter) with the mass per meter $\sim 15 \mathrm{~kg} / \mathrm{m}$. The lifting height is approximately $520 \mathrm{~m}$.
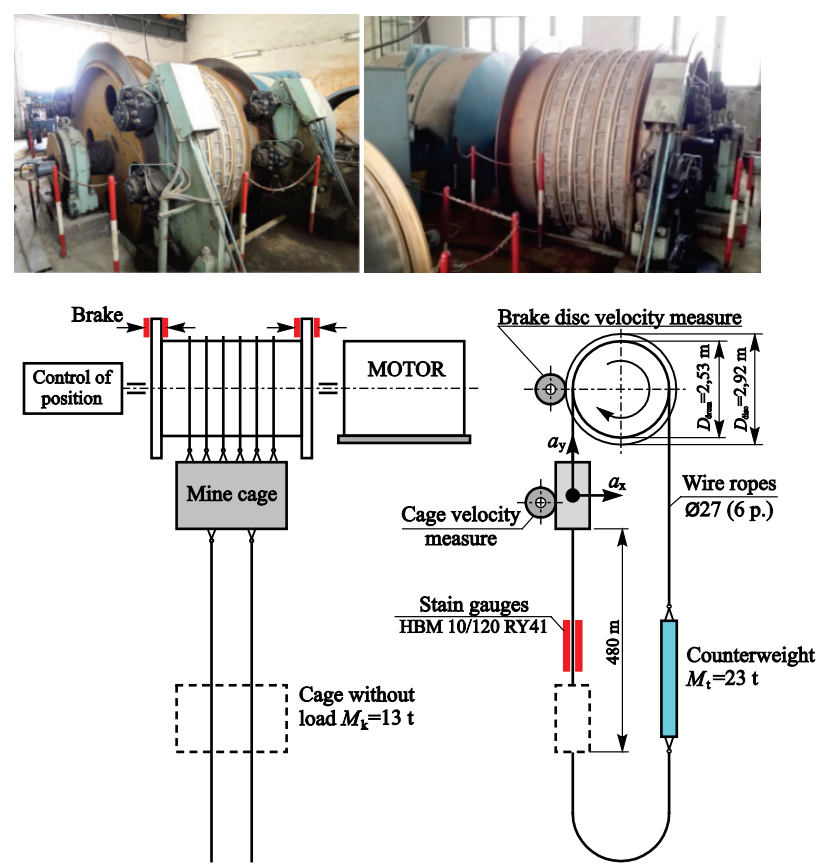

Figure17 Driving mechanism and the scheme of the positions for the measuring places

The driving mine shaft is of round cross section, and the diameter is $10 \mathrm{~m}$. The maximum designed lifting 
velocity of the cage is $16 \mathrm{~m} / \mathrm{s}$, but it is currently reduced to $4 \mathrm{~m} / \mathrm{s}$. Transfer of the force to the carrying elements (the ropes) is realised through friction (Koepe system) from the pulley with grooves, Fig. 17. The mine elevator is powered by electric-motor ASEA, HSDE-2.5 with the $\mathrm{rated} /$ pull power (torque) of $1500 / 2860 \mathrm{~kW}(117,2 / 233,4$ $\mathrm{kNm}$ ) and the maximum rotor speed of 122,2 rpm.

Measuring system consisted of a measuring amplifier HBM MGC+, a computer with HBM CATMAN-AP software, incremental encoder, triaxial acceleration sensor PHILIPS PR 9369/10 and two strain gauges positioned on the connection spot of the cage and the ropes (Fig. 18a). The complete measuring system in the first measuring series was set on the cage of the mine elevator, while the other series was conducted in the machine room where the lifting velocity was calculated according to data supplied by incremental encoder.

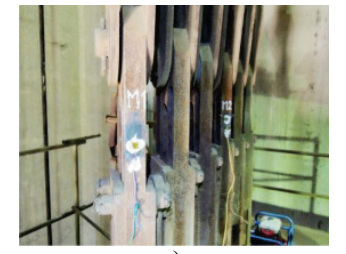

a)

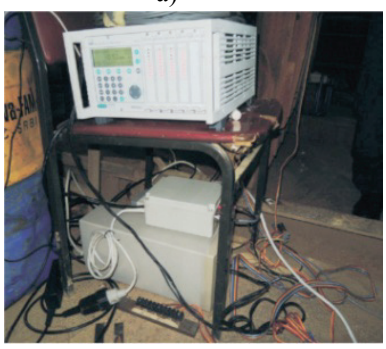

c)

Figure18 Part of measuring equipment on the cage (a), (b), (c) and in the machine room $(d)$

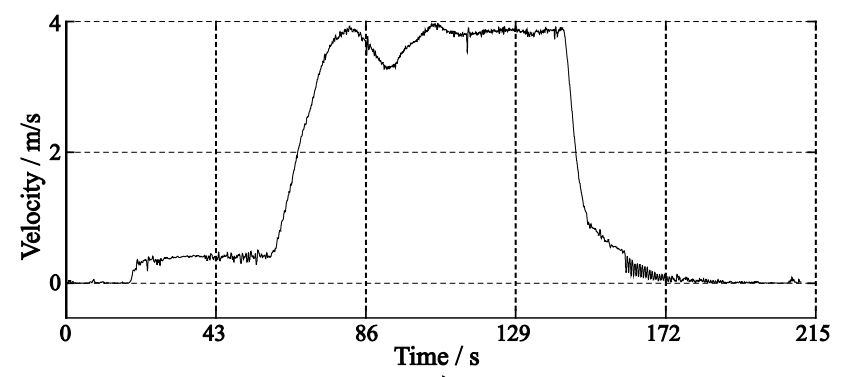

a)

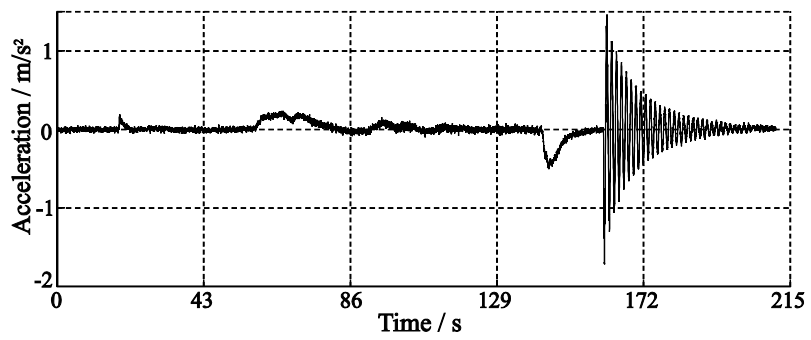

b)
Figure 19 Register of the velocity (a) and acceleration (b) on the cage

This paper is only going to show one part of the measuring results about the definition of stiffness, damping and lifting velocity in accordance with the discussions in Chapter 2. It is of importance to notice that due to certain limitations regarding the available measuring equipment and mine elevator safety protocols, it was impossible to simultaneously conduct the measurement on the cage and in the machine room. Fig. 19 shows the diagrams only as an illustration for the measured velocity and cage acceleration.

The determination of the parameters for a dynamic model will be shown for four movement cases, with and without a load:

a) Movement of the "full cage" (with a locomotive, mass $\sim 11 \mathrm{t}$ ) from the ground level to approximately the middle of the shaft $\sim 240 \mathrm{~m}$.

b) Movement of the full cage, with a locomotive, from the middle of the shaft downwards up to $\sim 480 \mathrm{~m}$.

c) Movement of an empty cage from the middle of the shaft downwards up to $\sim 480 \mathrm{~m}$.

d) Movement of an empty cage from the position $\sim 480$ $\mathrm{m}$ of the shaft up to $\sim 20 \mathrm{~m}$ upwards.

Fig. 20 shows schemes of those four cases after the pulley has stopped.

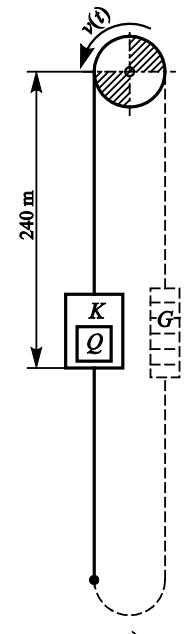

a)

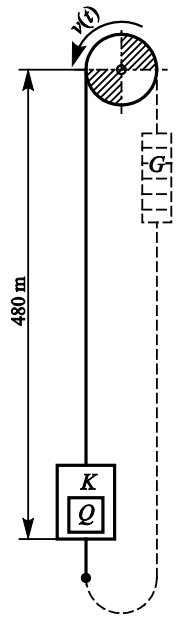

b)

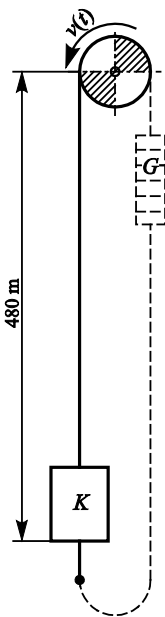

c)

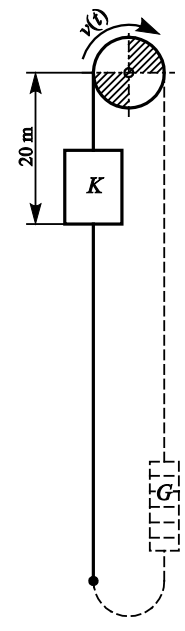

d)
Figure 20 Parameters of the mine elevator suitable for the analysis

As it was stated in Chapter 2, the stiffness and damping parameters can be derived from the measuring diagrams by defining the oscillation period, i.e. the frequency and logarithm decrement of the damping. As the Eqs. (14) and (15) are used in the case of free harmonic oscillations with damping, the relevant part of the diagram is the one which shows car oscillations after the pulley had been stopped. Fig. 21 shows the changes in acceleration of the cage in the above mentioned examples for periods when the cage is oscillating after the pulley had been stopped.

According to the analyses of the results shown in Tab. 2 and 3, it can be stated that the data used for the elasticity modulus is in accordance with the literature data $[2,12]$. That indicates the validity of the applied procedure which enables defining the real (drive) values with mine elevators. The values of the damping coefficient, for which there are no significant comparative data, are not of a constant magnitude. They rather differ in the analysed cases. It can be noted that the ratio $\delta / \omega$ shows similar dependence to the elasticity modulus, depending on the stress, and it is less dependent on the frequencies which is a characteristic of hysteretic damping. Only if measurements of a larger scale were performed could the more reliable conclusions be drawn. 
It is due to the boundaries during the experiments that a relatively small number of measurements for these parameters were conducted. Therefore, new measurements are planned in the same mine facility and on the experimental model in laboratory conditions.

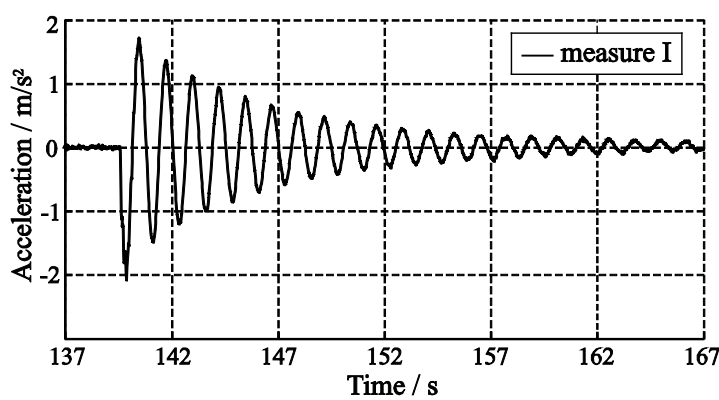

a)

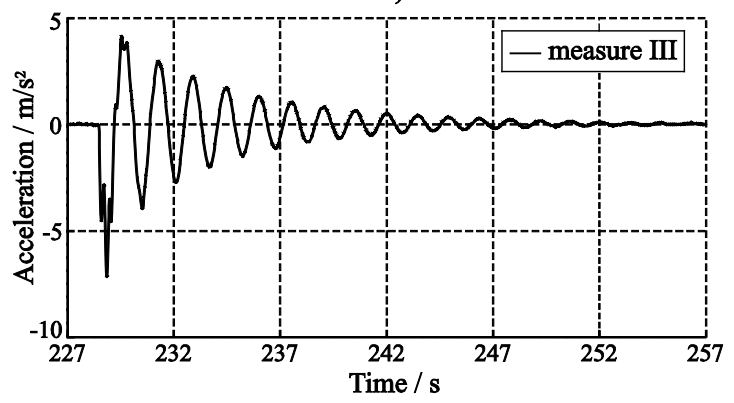

c)

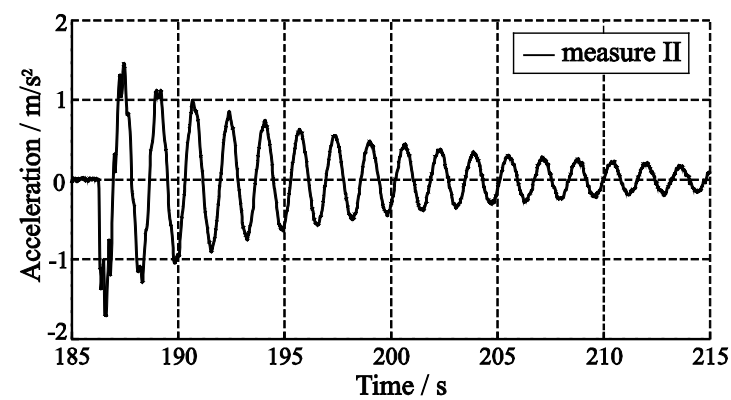

b)

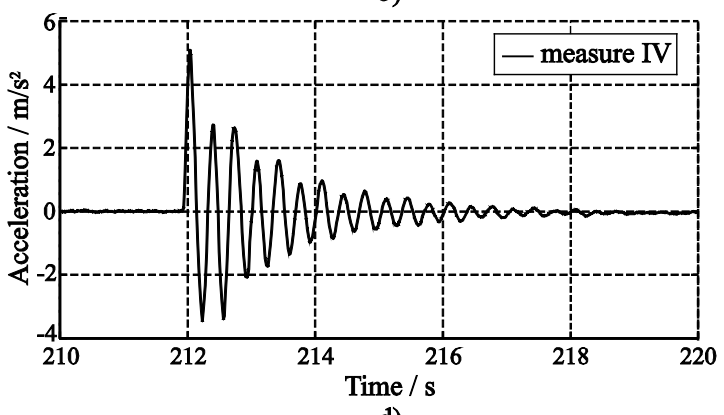

d)

Figure 21 Recorded acceleration values for the cage in the stated examples

Table 2 Values obtained through measurements

\begin{tabular}{|c|c|c|c|c|c|c|}
\hline & $M_{\mathrm{e}} / \mathrm{kg}$ & $L / \mathrm{m}$ & $T / \mathrm{s}$ & $\omega / \mathrm{rad} / \mathrm{s}$ & $x_{i} / \mathrm{m} / \mathrm{s}^{2}$ & $x_{i+1} / \mathrm{m} / \mathrm{s}^{2}$ \\
\hline I (Fig. 21a) $\downarrow$ & 31100 & $20 \div \mathbf{2 4 0}$ & 1,22 & 5,15 & 1,1263 & 0,9429 \\
\hline II (Fig. 21b) $\downarrow$ & 28700 & $240 \div \mathbf{4 8 0}$ & 1,66 & 3,77 & 0,9924 & 0,8508 \\
\hline III (Fig. 21c) $\downarrow$ & 17700 & $240 \div \mathbf{4 8 0}$ & 1,6 & 3,96 & 1,7424 & 1,3091 \\
\hline IV (Fig. 21d) $\uparrow$ & 22300 & $480 \div \mathbf{2 0}$ & 0,35 & 17,96 & 1,6248 & 1,2781 \\
\hline
\end{tabular}

Table 3 Calculated values

\begin{tabular}{|c|c|c|c|c|c|c|c|}
\hline & $\sigma / \mathrm{MPa}$ & $E / \mathrm{MPa}$ & $c / \mathrm{N} / \mathrm{m}$ & $D=\ln \left(x_{i} / x_{i+1}\right)$ & $b / \mathrm{Ns} / \mathrm{m}$ & $\delta / \mathrm{s}^{-1}$ & $\delta / \omega$ \\
\hline I (Fig. 21a) $\downarrow$ & 195,6 & 126908 & 824904 & 0,18 & 9295 & 0,15 & 0,029 \\
\hline II (Fig. 21b) $\downarrow$ & 180,5 & 125530 & 407972 & 0,14 & 5310 & 0,09 & 0,024 \\
\hline III (Fig. 21c) $\downarrow$ & 111,3 & 85377 & 277476 & 0,28 & 6143 & 0,17 & 0,043 \\
\hline IV (Fig. 21d) $\uparrow$ & 140,2 & 92219 & 7193116 & 0,24 & 30774 & 0,69 & 0,039 \\
\hline
\end{tabular}

$\sigma$-rope tensile stress, $E$ - elasticity modulus, $c$-stiffness coefficient, $D$ - logarithm decrement, $b$ - damping parameter, $\delta$ - damping coefficient.

\section{Computer simulations of the dynamic behaviour of the mine elevators}

Since the dynamic model parameters have been defined, it is possible to conduct different simulations of the dynamic behaviour of mine elevators by forming a differential equation of the motion and numeric integration using the different kinds of software. For our research we used software for an Automatic Dynamic Analysis of Mechanical Systems - MSC Adams. More details on the simulations and the possibilities of the software for the dynamic analysis of the system for vertical load lifting are provided in $[7,10]$.

Setting the motion in machines and facilities with vertical movement whose carrying (flexible) elements are winding onto a drum (steel ropes) is a problem which is not simple and easy to solve. Most software does not possess the tools to represent the carrying rope system the drum (driving pulley). In those cases it is necessary to use a combination of the existing tools to get satisfying results.
As it was previously explained in the second chapter, the driving characteristic is shown by setting the velocity, i.e. changes in the RPM of the driving pulley.

If we look at the problem of setting the function of the changes in the number of rotations of the electricmotor, we can do that in MCS Adams software by actually transforming that into setting the velocity in the time function for a certain marker on the rope in the direction in which the cage is being lifted. In that way, we are setting the motion on a translational joint, which can offer a simplified model of the connection between the rope and the driving pulley.

Defining the velocity as a function over the time can be done in a few ways. One of them is to define the velocity through a combination of a Heaviside step function with a cube polynomial, together with a linear dependence velocity-time [10].

The other way, which was used in this paper, was to set the velocity change in a form of "spline" which undoubtedly describes the change in the rotational velocity of a driving electric-motor which is in relation to 
the circumferential velocity of the drum, i.e. driving pulley, that was gained by direct measuring on the driving pulley by an incremental encoder. The "spline" used in the software, represents a medium line of the measured circumferential velocity of the driving pulley, which eliminates the so-called measure "frequency", Fig. 22.

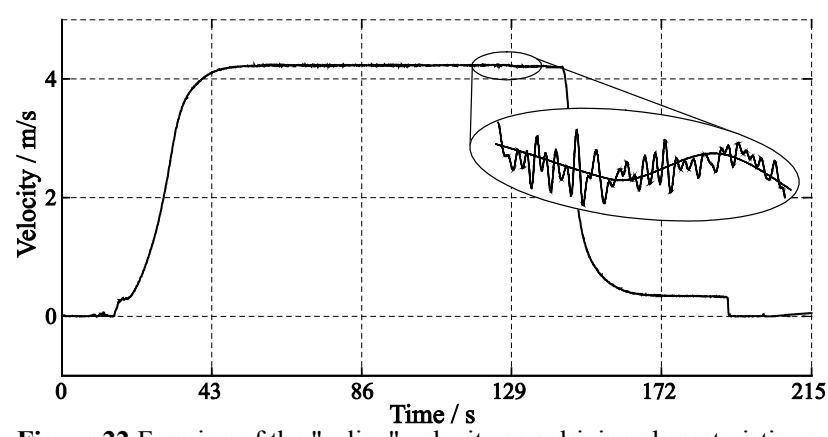

Figure 22 Forming of the "spline" velocity as a driving characteristic on the pulley

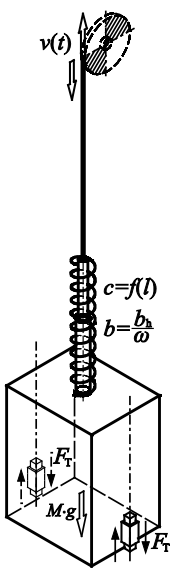

Figure 23 Computer model of exploitation facilities

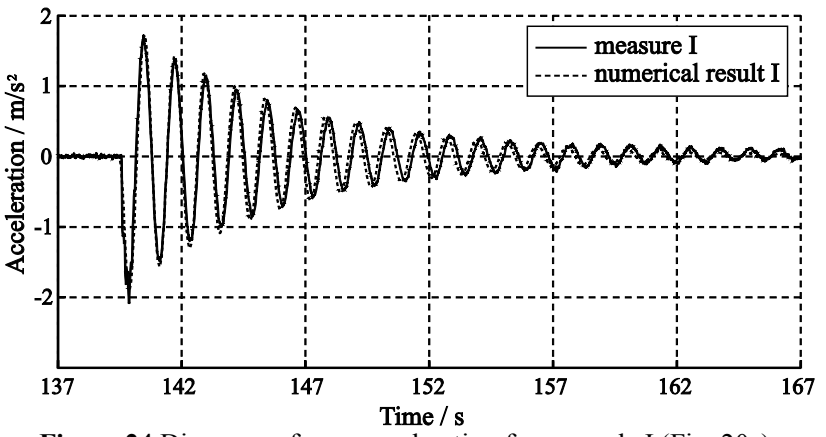

Figure 24 Diagrams of cage acceleration for example I (Fig. 20a)

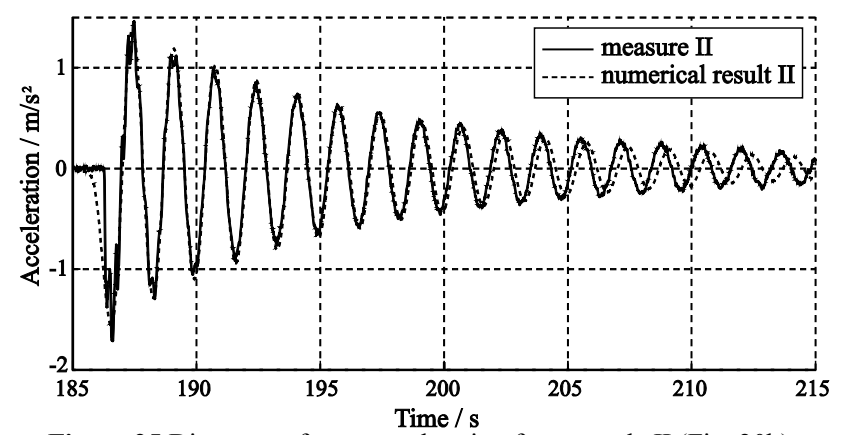

Figure 25 Diagrams of cage acceleration for example II (Fig. 20b)

According to the previous diagrams it can be concluded that the dynamic model and the model parameters describe, with satisfying accuracy, the realistic behaviour of mine elevators, thus enabling their detailed analysis, which is not the purpose of this paper. As an illustration of the possibilities of dynamic analysis there is a diagram of the change of certain values drawn in the software for dynamic analysis (MSC Adams). In that case the change in stiffness and damping is included through a variable force between the marker on the pulley and the marker that shows the connection between the ropes and the cage, in accordance with the data shown in Tab. 3 .

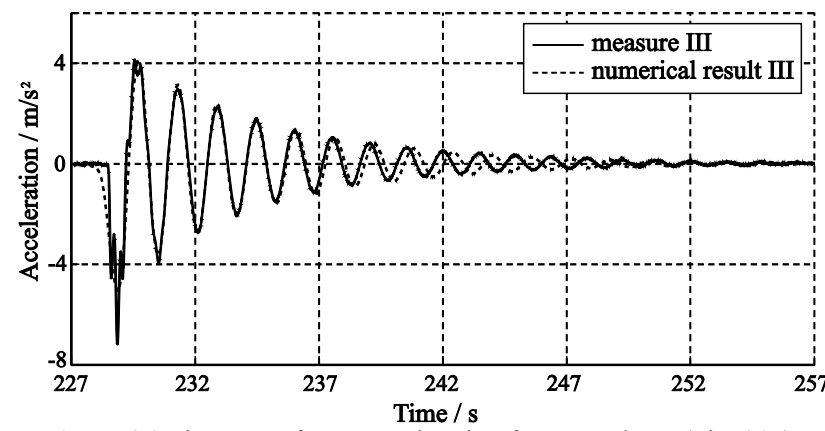

Figure 26 Diagrams of cage acceleration for example III (Fig. 20c)

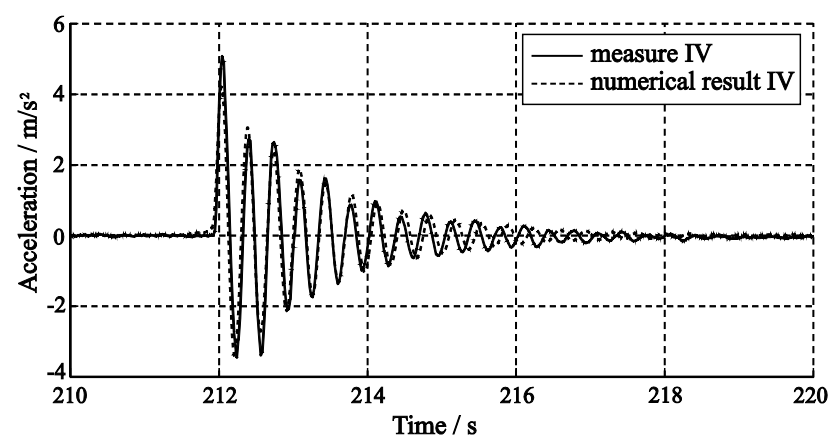

Figure 27 Diagrams of cage acceleration for example IV (Fig. 20d)

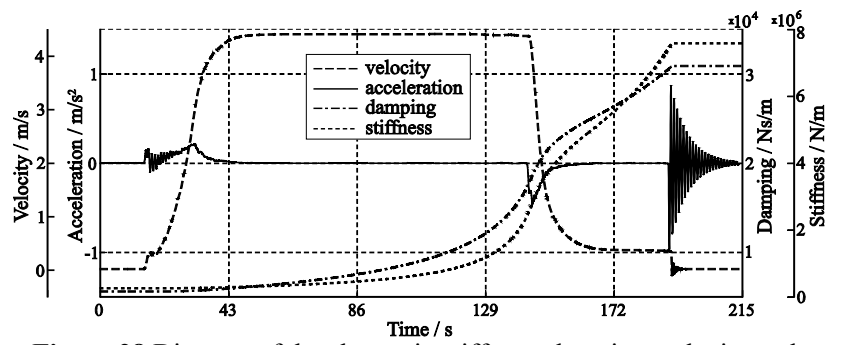

Figure 28 Diagram of the change in stiffness, damping, velocity and acceleration while lifting the cage

\section{Conclusion}

Mine elevators are used in the mines with underground exploitation at the depths as deep as $2000 \mathrm{~m}$ with the carrying capacity of maximum $30 \mathrm{t}$ and the lifting velocities of up to $20 \mathrm{~m} / \mathrm{s}$. Therefore, their analysis is of special interest because they define the quality basis for optimal projecting and their maintenance in relatively heavy working conditions.

Apart from the mentioned extreme parameters, the complexity of the dynamic analysis of these facilities is primarily due to these facts:

- The basic model is an oscillatory problem with an infinite number of DOF and it is influenced by a large number of factors,

- The driving torque is a variable value (the function of the pulley rotational speed and the operating load), 
- The stiffness of the wire rope varies with the changes in the cage position, causing parametric oscillations,

- Steel rope elasticity modulus is not a constant value, as it is the case with homogenous bodies. It depends on rope structure, stress level and how long the rope was in service.

- Damping in the wire rope is a feature which has not been sufficiently examined. It is a consequence of the inner friction of a hysteretic type, depending on the construction of the rope, stress in the rope, contact type and friction between the wires, then lubrication, oscillation amplitudes etc.

- The influence of friction in the guide rails on the damping of the whole system cannot be ignored.

By analysing the parameters of a specific mine elevator it is possible to significantly simplify the basic model and to gain a model suitable for dynamic analysis. The system with an infinite number of DOF has come down to a system with one DOF and a forced movement which was modelled according to the velocity measured on the pulley. It is also possible to replace the rope system with the equivalent Kelvin's model with variable stiffness ( $c=E \cdot A / l)$ and damping. By combining theoretical analysis with an experimental procedure it is possible to define the real values of elasticity modulus and damping, with the results of measuring the oscillation periods and amplitudes at the moment when the driving pulley is stopped. Modulus values which are defined in this way indicate an important dependence of the elasticity modulus on the load, i.e. stress. Damping coefficient is not a constant value, like with the model of viscous friction. It depends on the frequency, or the cage position, just like stiffness, and ratio $(\delta / \omega)$ indicates that hysteretic damping is overwhelming and it should be examined in greater details. In order to obtain more reliable results and a more detailed analysis of stiffness and damping in such facilities, greater measuring should be conducted in both real and laboratory conditions. It should be taken into consideration even though the basic model is very simplified, the analysis of a formed dynamic model, due to its variable parameters, can be realised only with the usage of numeric methods or suitable software.

\section{References}

[1] Beards, C. F. Engineering Vibration Analysis with Application to Control Systems. Edward Arnold - Hodder Headline Group, London, 1995.

[2] Feyrer, K. Wire Ropes. University of Stuttgart, Germany, 2007. DOI: $10.1007 / 978-3-540-33831-4$

[3] Silva, C.W. Vibration, Damping, Control and Design. CRC Press - Taylor \& Francis Group, Boca Raton, Florida, 2007.

[4] Vergne, J. N. The Hard Rock Miner's Handbook, Edition 3. McIntosh Engineering Limited, Ontario, Canada, 2003.

[5] Vladić, J. Prilog određivanju stepena sigurnosti protiv proklizavanja dinamički opterećenog užeta u sistemu prenosa snage pogonskom užnicom. Magistarski rad, Novi Sad, 1982.

[6] Vujanović, B. Teorija oscilacija, Univerzitet u NovomSadu, 1995.

[7] Đokić, R. Razvoj analitičko-numeričkih postupaka za određivanje dinamičkog ponašanja liftova. Magistarski rad, Novi Sad, 2010.
[8] Herrera, I.; Su, H.; Kaczmarczyk, S. Investigation into the damping and stiffness characteristics of an elevator car system. // Applied Mechanics and Materials. 24-25, (2010), pp. 77-82. DOI: 10.4028/www.scientific.net/AMM.24-25.77

[9] Pakdemirli, M.; Ulsoy, A. G. Stability analysis of an axially accelerating string. // Journal of Sound and Vibration. 203, 5(1997), pp. 815-832. DOI: 10.1006/jsvi.1996.0935

[10] Vladić, J.; Đokić, R.; Kljajin, M.; Karakašić, M. Modelling and simulations of elevator dynamic behaviour. // Tehnički vjesnik/Technical Gazette. 18, 3(2011), pp. 423-434.

[11] Vladić J.; Malešev, P.; Šostakov, R.; Brkljač N. Dynamic analysis of the load lifting mechanisms. // Strojniški vestnik. 54, 10(2008), pp. 655-661.

[12] Горошко О. А.; Артюхова В.Е. Зависимость коэффициентов рассеяния энергии в канате от егнатяжения. // В кн.: Стальные канаты 5 / Киев, 1968, pp. 57-58.

[13] Хромов, О. В. Выбор модели внутреннего трения на основе экспериментальных осциллограмм затухающих колебаний системы. // Зб. наук.: Механика, энергетика, экология / Севастополь, 2010, pp. 35-39.

\section{Authors' addresses}

Prof. dr. sc. Jovan Vladic

Mr. sc. Radomir Djokic

University of Novi Sad, Faculty of Technical Sciences

Trg D. Obradovića 6, 21000 Novi Sad, Serbia

E-Mail: vladic@uns.ac.rs

E-Mail: djokic@uns.ac.rs

Prof. dr. sc. Miomir Jovanovic

University of Niš, Mechanical Engineering Faculty

Aleksandra Medvedeva 14, 18000 Niš, Serbia

E-mail:miomir@masfak.ni.ac.rs

\section{Prof. dr. sc. Milan Kljajin}

Doc. dr. sc. Mirko Karakašić

J. J. Strossmayer University of Osijek

Mechanical Engineering Faculty in Slavonski Brod

Trg Ivane Brlić-Mažuranić 2, 35000 Slavonski Brod, Croatia

E-mail:mkljajin@sfsb.hr

E-mail: mirko.karakasic@sfsb.hr 